University of Nebraska - Lincoln

DigitalCommons@University of Nebraska - Lincoln

Faculty Publications, Department of Psychology

Psychology, Department of

2011

\title{
Exploring Separable Components of Institutional Confidence
}

Joseph A. Hamm

University of Nebraska-Lincoln, jhamm2@unl.edu

Lisa M. Pytlik Zillig

University of Nebraska-Lincoln, Ipytlikz@nebraska.edu

Alan Tomkins

University of Nebraska Public Policy Center, atomkins@nebraska.edu

Mitchel Herian

University of Nebraska-Lincoln, mherian2@unl.edu

Brian H. Bornstein

University of Nebraska-Lincoln, bbornstein2@unl.edu

See next page for additional authors

Follow this and additional works at: https://digitalcommons.unl.edu/psychfacpub

Part of the Psychiatry and Psychology Commons

Hamm, Joseph A.; Pytlik Zillig, Lisa M.; Tomkins, Alan; Herian, Mitchel; Bornstein, Brian H.; and Neeley, Elizabeth, "Exploring Separable Components of Institutional Confidence" (2011). Faculty Publications, Department of Psychology. 548.

https://digitalcommons.unl.edu/psychfacpub/548

This Article is brought to you for free and open access by the Psychology, Department of at DigitalCommons@University of Nebraska - Lincoln. It has been accepted for inclusion in Faculty Publications, Department of Psychology by an authorized administrator of DigitalCommons@University of Nebraska - Lincoln. 
Authors

Joseph A. Hamm, Lisa M. Pytlik Zillig, Alan Tomkins, Mitchel Herian, Brian H. Bornstein, and Elizabeth Neeley

This article is available at DigitalCommons@University of Nebraska - Lincoln: https://digitalcommons.unl.edu/ psychfacpub/548 


\title{
Exploring Separable Components of Institutional Confidence
}

\author{
Joseph A. Hamm, B.A., Lisa M. PytlikZillig, Ph.D., \\ Alan J. Tomkins, J.D., Ph.D., Mitchel N. Herian, Ph.D., \\ Brian H. Bornstein, Ph.D., and Elizabeth M. Neeley, Ph.D. \\ University of Nebraska-Lincoln, Lincoln, Nebraska USA
}

Corresponding author - Alan J. Tomkins, Public Policy Center, 215 Centennial Mall South, Suite 401, Lincoln, NE 68588-0228, U.S.A; email: atomkins@nebraska.edu

\begin{abstract}
Despite its contemporary and theoretical importance in numerous social scientific disciplines, institutional confidence research is limited by a lack of consensus regarding the distinctions and relationships among related constructs (e.g., trust, confidence, legitimacy, distrust, etc.). This study examined four confidence-related constructs that have been used in studies of trust/confidence in the courts: dispositional trust, trust in institutions, obligation to obey the law, and cynicism. First, the separability of the four constructs was examined by exploratory factor analyses. Relationships among the constructs were also assessed. Next, multiple regression analyses were used to explore each construct's independent contribution to confidence in the courts. Finally, a second study replicated the first study and also examined the stability of the institutional confidence constructs over time. Results supported the hypothesized separability of, and correlations among, the four confidence-related constructs. The extent to which the constructs independently explained the observed variance in confidence in the courts differed as a function of the specific operationalization of confidence in the courts and the individual predictor measures. Implications for measuring institutional confidence and future research directions are discussed.
\end{abstract}

\section{INTRODUCTION}

Public confidence in institutions has been the focus of much general, political, and academic attention. Confidence in the judicial system has been a particular focus of much of the institutional confidence research (Benesh, 2006; Benesh \& Howell, 2001; Dougherty, Lindquist, \& Bradbury, 2006; Gastil, Deess, Weiser, \& Simmons, 2010; National Center for State Courts, 1999; Wenzel, Bowler, \& Lanoue, 2003). At a policy level, confidence in the courts is one of the key ingredients of a responsive judiciary. As Justice Sandra Day O'Connor (1999) observed, "Sometimes, in the pressure of doing what judges have to do and running a tight ship in the courtroom and deciding tough issues, we might forget that, in the last analysis, it is, after all, the public we serve and that we do care how the courts are perceived generally" (p. 10, emphasis added). 
A decade ago, the National Center for State Courts, in partnership with the American Bar Association, Conference of Chief Justices, Conference of State Court Administrators, and the League of Women Voters, developed a national action plan as a guide to state and national organizations for increasing public trust and confidence in the courts (Leben, 1999; National Center for State Courts, 2000). Trust/ confidence is one of five performance standards by which trial courts can assess themselves (National Center for State Courts, 2005).

What is being measured when we ask the public about their trust, confidence, or related constructs like their loyalty or cynicism toward an institution? It turns out that at both conceptual and empirical levels, it is unclear. As Nannestad (2008) observed in a recent review, at the conceptual level, "There is not even agreement on the category to which confidence belongs" (p. 414). Numerous terms and constructs related to confidence in the courts and other institutions reveal numerous terms and constructs that are used virtually interchangeably (e.g., Bigley \& Pearce, 1998; Cook \& Gronke, 2005; Leben, 1999; Newton, 2001; Rottman \& Tomkins, 1999; Rousseau et al., 1998; Suchman, 1995). Positive-valence terms include confidence, trustworthiness, legitimacy, loyalty, and support, as well as a variety of forms of trust (e.g., dispositional, diffuse, specific, political, interpersonal, etc.). Negative-valence terms include constructs such as skepticism, cynicism, and distrust. Examination of confidence-related terms within and across disciplines reveals discrepancies in how - and even whether-they are defined, distinguished from, or conceptually related to one another (compare, e.g., Gibson, Caldeira, \& Spence, 2003; Gross, Brewer, \& Aday, 2009; Tyler, 1990/2006). For example, the terms trust and confidence are often used interchangeably, but they also have been distinguished in terms of both motives (Hardin, 2006) and active and reflective choices (D'Amico, 2003; Mayer, Davis \& Schoorman, 1995/2006).

To begin to understand institutional confidence and its related constructs, and how these various constructs relate to each other, this article reports on two studies that examine distinctions in selected institutional confidence-related constructs in the context of the courts. Through our investigation, we hoped to increase understanding of both confidence in the courts and theoretical and empirical distinctions among related (e.g., trust and confidence), but hypothetically different, constructs. We evaluated construct stabilities and associations over time, and explored their ability to account for independent variance in typical measures of confidence in the courts (see Figure 1).

Based on our review of conceptual definitions and measures, the constructs we chose as likely to be distinct from one another and to contribute to self-reported

\section{Confidence-related constructs}

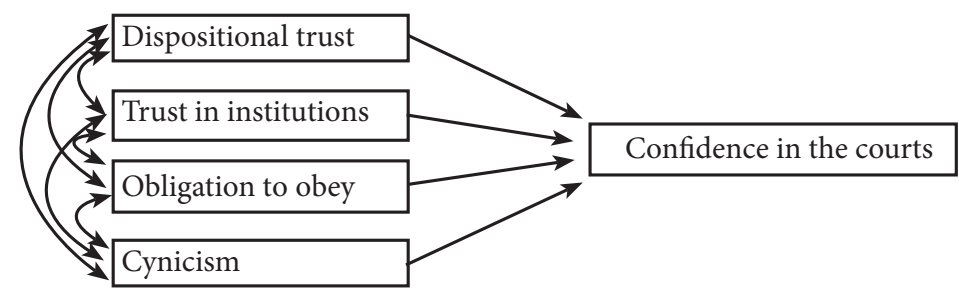

Figure 1. Hypothesized model of four correlated but separable confidence-related constructs predicting confidence in a specific institution, the courts. 
confidence in the courts were constructs that varied in specificity (e.g., the disposition to trust in general versus trust in public institutions), expectational focus of the trustor (i.e., focus outward on the obligations of the trusted institutions vs. focus inward on the trustor's own obligations, e.g., to obey the institutions), and valence of the confidence-related construct (e.g., positive trust vs. negative cynicism). Specifically, we hypothesized that people's dispositional trust across situations, trust in institutions, felt obligation to obey the law, and cynicism toward the law are separable constructs that have independent relationships with, and independently contribute to, reported confidence in the courts.

Thus, our primary criterion construct was confidence in the courts. Confidence in courts, or other institutions for that matter, is not consistently operationalized or measured across studies. Three typical ways to assess either confidence or trust are: (1) direct assessment with a single item such as "How much confidence do you have in the courts?" (National Center for State Courts, 1999; Tyler \& Huo, 2002; see also items from large-scale national surveys such as the General Social Survey [GSS] and National Election Study [NES]), ${ }^{1}$ which leaves the definition of confidence/trust unspecified; (2) assessment of the factors that reflect perceptions of trustworthiness, including perceptions of the integrity, competence, and motives of the target, such as "Judges are generally honest and fair in deciding cases" (Hoy \& Tschannen-Moran, 2003; Mayer et al., 1995/2006; National Center for State Courts, 1999; Wenzel, Bowler, \& Lanoue, 2003); and (3) questions about whether people trust the target to meet specific expectations presumed to be relevant to the institution and likely to be valued by the trustor (e.g., whether the respondent has confidence that courts will uphold the law) (Tyler, 1990/2006; Tyler \& Huo, 2002; Wenzel et al., 2003). Because other researchers have shown that different operationalizations of very similar constructs can lead to different results (Cook \& Gronke, 2005; Gibson, Caldeira, \& Spence, 2003), ${ }^{2}$ in Study 1 we compare the results obtained from three different models, using three different measures of confidence in the courts as the criterion variable.

The most general of our predictor variables was dispositional trust, which is typically defined as a personality trait or predisposition of a person to trust others or to expect others to be trustworthy (Nannestad, 2008; Rotter, 1967, 1971). Thus, the "target" of dispositional trust can be quite broad - seemingly including a person's disposition to trust across all targets, time, and situations. Although dispositional trust has been criticized, and some have shown or theorized trust to be domain-specific (Hardin, 2006; Nannestad, 2008), it nonetheless has been found to predict confidence in specific institutions (D'Amico, 2003). Also, the sheer amount of research that includes items assessing dispositional trust makes worthwhile the further examination of its relation to other confidence-related constructs.

Trust in institutions, our second predictor variable, is much like dispositional trust in the sense that it is intended to reflect one's tendencies over time and situations except that it, much like diffuse support for institutions, focuses on institutions specifically. We hypothesized its separability and independent contribution to confidence in the courts, however, because in contrast to dispositional trust, it focuses on a more specific or narrower target - trust in institutions or the

1. NES is retrievable at http://www.electionstudies.org/ ; GSS at http://www.norc.org/ GSS+Website

2. However see, for example, National Center for State Courts (1999, p. 12, Table 1), showing there was no difference in results whether respondents were asked about their "confidence" versus their "trust" in various institutions. 
leaders of institutions, rather than trust in people in general. Compared with dispositional trust, we also expected trust in institutions to be more closely related to confidence in the courts, which focuses on an even narrower target, a single institution. The advantage of assessing a person's trusting tendencies toward targets of varying breadths is that we can begin to untangle the extent to which, and the conditions under which, trust in a specific institution is due to "general" versus relatively more "domain-specific" factors. Some researchers (D'Amico, 2003; Mayer et al., 1995/2006; see also Kramer, 1999) have theorized and documented that the sources of institutional trust change over time such that, prior to having experience with an institution, confidence in a specific institution is related to dispositional trust. With time and experience with that institution, dispositional trust becomes less predictive and domain-relevant experience becomes more predictive.

Obligation to obey the law, a construct related to institutional legitimacy, was our third hypothesized distinct predictor of confidence in the courts. Institutional legitimacy evaluations are argued to be pivotally important in encouraging public compliance with institutions (Tyler, 1990/2006). Tyler calls it the primary alternative to power as a source of the compliance necessary for the functioning of an institution. The courts' "lack of control of the purse or the sword" seriously hinders their ability to use an instrumental strategy (power) for compliance and, as such, makes a normative strategy (highlighting its legitimacy) very important (Gibson, 2008, p. 61). Leading researchers disagree as to the connection between institutional legitimacy and obligation to obey. Tyler conceptualizes obligation to obey as a component of legitimacy (e.g., Tyler \& Fagan, 2008; Tyler \&Huo, 2002) while Gibson considers it an outcome (e.g., Gibson \& Caldeira, 1998). In both cases, however, there is no question that the two constructs are correlated. The extent to which one feels that one should obey a target is distinct and likely separable from tendencies or dispositions to trust in that, when considering trust, one's expectations focus on the target's responsibilities to the trustor. Obligation to obey, however, shifts the expectational focus to the trustor's reciprocal felt responsibility to the target. Stated differently, dispositional trust and trust in institutions consider the target's actions towards to the trustor, while obligation to obey is concerned with the trustor's actions towards the target.

Finally, the fourth predictor variable was cynicism. We hypothesized that cynicism would be separable from other constructs, and independently predictive of confidence in the courts, on the basis of its different valence. Our hypotheses were consistent with others who have argued that, in order to understand institutional confidence, both positive and negative constructs must be considered (Cook \& Gronke, 2005; Lewicki, McAllister, \& Bies, 1998).

\section{STUDY 1}

\section{Method}

The primary goal of Study 1 was to explore the independence, overlap, and structure of the four hypothesized separable confidence-related constructs, and their relationships with and independent contributions to, three different 
operationalizations of confidence in the courts. As we explain in greater detail below, our studies of two undergraduate samples used measures taken directly or adapted from others that have been used to study these institutional confidencerelated constructs.

\section{Primary constructs and measures}

All items used to assess confidence and the confidence-related constructs (listed in Appendix 1) were administered as part of a survey asking participants to rate the extent to which they agreed with various institutional confidence-related statements. Unless otherwise noted, all items were scored on seven-point scale ranging from 1 (strongly agree) to 7 (strongly disagree). Before combining into scales, negatively worded items were re-coded so that lower numbers would indicate more of the construct measured.

Confidence in the courts. Confidence in the courts was our criterion variable. To assess the three common operationalizations of confidence in the courts, we used three measures. The first measure, assessing "unspecified confidence" in the courts, was a single item used by Tyler and Huo (2002), which simply asked participants to rate how much confidence they had in the courts in their community. The second measure comprised six items that focused on perceptions of "trustworthiness" of the courts by asking participants to indicate their agreement with statements like: "Most judges in my community do their jobs well" and "Most judges in my community are dishonest" (reverse scored) (Tyler \& Huo, 2002). The last measure comprised six items directed at more "specific expectations" of the courts, such as "Courts protect defendants' constitutional rights" and "Most juries are representative of the community" (National Center for State Courts, 1999; Wenzel, Bowler, \& Lanoue, 2003).

Dispositional trust. We measured dispositional trust using a three-item scale regularly used in the NES and GSS. The scale asks participants to respond about their perceptions of the motives of "most people." Specifically the scale uses three (sevenpoint) bipolar response scales to ask whether the participant believes that most people would be helpful or only look out for themselves, whether people are generally fair or take advantage of others, and whether the participant trusts most people or feels that one cannot be too careful (see Appendix 1). Our previous work (University of Nebraska Public Policy Center, 2009) included this and another measure of dispositional trust based on the five-factor model of personality, in which trust is a facet of agreeableness (Goldberg, 1999). In our work, we found the two scales were highly correlated $(r(109)=.65, p<.001)$.

Trust in institutions. We assessed trust in public institutions using three questions that have been widely used as part of the GSS and the NES. Using the same stem but changing the target, these items ask how much of the time participants feel they can trust local, state, and federal government to do what is right. ${ }^{3}$

3. Given our focus on government, this scale may be more aptly titled "trust in government institutions." However, we broadened it to other, non-governmental institutions in Study 2. 
Obligation to obey the law. To assess obligation to obey, we used three items from Tyler and Huo (2002) that ask participants to respond with their level of agreement with statements such as, "I feel I should accept the decisions of legal authorities."

Cynicism toward the law. Cynicism in this study followed Tyler's approach and was conceptualized as a participants' belief the law was "against them" (Tyler \& Huo, 2002, p. 104). It was measured using the three-item scale from Tyler and Huo's (2002) study. The scale asks participants to indicate their agreement with statements such as, "The law does not protect my interests" and "People in power use the law to control people like me."

\section{Participants and data collection procedures}

Participants comprised 120 students from the University of Nebraska-Lincoln recruited from political science and psychology classes to take an online survey to assess their confidence in courts. Participants were mostly female (62\%) and had an average age of 20.8 (SD $=4.42$, range $18-41$ ) years. They completed the survey outside of the classroom and received extra credit for their participation. The web-based program administering the survey (Qualtrics.com) kept track of completion time, which ranged from 1 to 89 minutes and was approximately $11 \mathrm{~min}$ utes on average. ${ }^{4}$

\section{Results}

\section{Factor analyses}

Our first analysis aimed simply to find out whether the items would return to the scales we originally took them from. We analyzed all 25 items (i.e., all items from the three confidence in the courts criterion variables and the four confidence-related predictor variables) using exploratory factor analysis ${ }^{5}$ with a principal components extraction and an eigenvalue criterion of one. All items returned communalities greater than .45 , indicating shared variance. Additionally, all items correlated with at least one other item greater than .3, indicating reasonable factorability. Seven factors were extracted which were then subjected to oblique (Promax) rotation, because we expected the factors to be correlated. The seven-factor solution accounted for $68 \%$ of the variance in the responses, but the structure matrix was largely unintelligible because of a great deal of multivocality (16 items had at least one cross-loading above .4, and three of those items had at least one item above .6). Nonetheless, the items assessing the four hypothesized separable confidencerelated predictor constructs (i.e., dispositional trust, trust in institutions, obligation to obey, and cynicism) all had their highest loadings (with all primary loadings >

\footnotetext{
4. Scale means with and without participants completing the survey in less than 5 minutes were negligibly different; consequently, we did not eliminate the data from the participants who completed the survey quickly.

5. Exploratory analyses were used because the structure of the items used in this study had not been previously tested. Although it could be argued that, because we used scales from the literature, confirmatory analyses might be more appropriate, these scales have never been used together in a single research endeavor and, as such, exploratory factor analyses were deemed more appropriate.
} 
.6) on distinct factors. The items used to assess the criterion of confidence in the courts tended to load on all seven factors with no clear indication of an independent factor.

We next conducted additional exploratory factor analyses using only the items hypothesized to assess the four predictors. Once again, all items returned communalities greater than .3, indicating shared variance, and all items correlated with at least one other item greater than .3, indicating reasonable factorability. We conducted both principal components (PC) and common factors (principal axis factoring; PAF) factor analyses. Unlike PC analysis, which extracts factors to maximize the variance in responses, PAF starts with an incomplete correlation matrix based only on the shared variance which may be presumed to relate to the underlying constructs (Warner, 2007). PC analyses are better suited for reducing the number of variables while still maximizing variance accounted for by the new factors, and PAF analyses are adept at identifying whether and how many different latent factors underlie the items.

The PC factor analysis with an eigenvalue greater than one criterion and Promax rotation revealed a four-factor solution accounting for $67 \%$ of the variance in responses. As shown in Table 1, the structure matrix revealed a clear factor structure with the remaining four related construct scale items loading together on independent factors with only limited multivocality (each item's primary loading was greater than .65 and no item had cross-loadings greater than .50). The four rotated factors, named for the scale items that loaded on them - dispositional trust, trust in institutions, obligation to obey the law, cynicism toward the law - accounted for high to moderate proportions of the variance: cynicism $=25 \%$, trust in institutions $=$ $23 \%$, obligation to obey $=20 \%$, and dispositional trust $=18 \%$.

The PAF, using an eigenvalue greater than one criterion and Promax rotation of the same 12 items, revealed the same four-factor solution as in the PC analysis, this time accounting for $52 \%$ of the shared variance in responses. Although it was somewhat less clear than the PC analysis, ${ }^{6}$ the PAF structure matrix confirmed our previous factor structure and left scale items together on independent factors with only limited multivocality (each item loaded on its scale greater than .55 and no item loaded on any other scale higher than .45). The rotated factors accounted for the variance in responses as follows: cynicism $=23 \%$, trust in institutions $=20 \%$, obligation to obey $=18 \%$, and dispositional trust $=15 \%$.

\section{Construct interrelationships}

We next created scales by averaging across relevant items to create measures of the four confidence components (items grouped as listed in Table 1) and each of the confidence in the courts multi-item scales. Scale internal reliabilities, means, standard deviations, and intercorrelations are presented in Table 2. Internal reliabilities were adequate, especially given the small number of items per scale, but also showed room for improvement. Notably, all correlations were statistically significant and the highest correlations tended to occur between the three operationalizations of confidence in the courts. However, the highest correlation (.70) still

6. Because there were only three items per scale, some of the non-shared item variance that was omitted from the PAF but included in the PC analysis may have been related to the underlying construct, resulting in a clearer factor structure based on the full (PC) rather than the partial (PAF) correlation matrix. 
Table 1. Study 1: Univariate statistics and factor loadings for exploratory principal components (Promax rotation) factor analysis of items assessing institutional confidence-related constructs

\begin{tabular}{|c|c|c|c|c|c|c|c|}
\hline \multirow[t]{2}{*}{ Items } & \multirow[b]{2}{*}{$M$} & \multirow[b]{2}{*}{$(\mathrm{SD})$} & \multirow[b]{2}{*}{$N$} & \multicolumn{4}{|c|}{ Factor loadings } \\
\hline & & & & $\begin{array}{l}\text { Cynicism } \\
\text { towards } \\
\text { the law }\end{array}$ & $\begin{array}{c}\text { Average } \\
\text { trust in } \\
\text { institutions }\end{array}$ & $\begin{array}{l}\text { Obligation } \\
\text { to obey } \\
\text { the law }\end{array}$ & $\begin{array}{c}\text { Dispo- } \\
\text { sitional } \\
\text { trust }\end{array}$ \\
\hline \multicolumn{8}{|l|}{ Dispositional trust } \\
\hline Disp1 & 4.89 & $(2.95)$ & 118 & -.14 & .31 & -.01 & .77 \\
\hline Disp2 & 4.44 & (1.87) & 117 & .25 & -.11 & -.27 & -.80 \\
\hline Disp3 & 4.04 & $(1.79)$ & 118 & -.29 & .25 & .10 & .75 \\
\hline \multicolumn{8}{|l|}{ Trust in institutions } \\
\hline Trust federal & 2.9 & $(.91)$ & 117 & -.30 & .82 & .16 & .22 \\
\hline Trust state & 2.56 & $(.87)$ & 117 & -.27 & .89 & .22 & .20 \\
\hline Trust local & 2.39 & $(.75)$ & 117 & -.34 & .69 & .41 & .24 \\
\hline \multicolumn{8}{|l|}{ Obligation to obey the law } \\
\hline Accept legal authority & 3.39 & $(1.43)$ & 118 & -.50 & .43 & .73 & .20 \\
\hline Obey against morals & 4.00 & $(1.76)$ & 117 & -.31 & .31 & .76 & -.10 \\
\hline $\begin{array}{l}\text { Hard to break law } \\
\text { and respect self }\end{array}$ & 3.69 & $(1.70)$ & 118 & -.11 & .07 & .80 & -.19 \\
\hline \multicolumn{8}{|l|}{ Cynicism toward the law } \\
\hline Law represents powerful & 3.39 & $(1.426)$ & 118 & .84 & -.43 & -.31 & -.19 \\
\hline Law used to control me & 3.70 & (1.521) & 117 & .88 & -.20 & -.18 & -.23 \\
\hline $\begin{array}{l}\text { Law doesn't protect } \\
\text { my interests }\end{array}$ & 4.53 & $(1.512)$ & 118 & .82 & -.33 & -.41 & -.27 \\
\hline
\end{tabular}

Items are grouped by a priori scale. Loadings above .6 are in bold. $M=$ mean and $N=$ number of participants who responded to the question; $\mathrm{SD}=$ standard deviation.

indicated that only $50 \%$ of the variance was shared between the different measures, and thus that the operationalizations were not equivalent.

\section{Regression analyses}

We next conducted a series of multiple regressions to examine the hypothesized independent effects of the confidence-related construct scales on each of the confidence in the courts criterion measures. Preliminary analyses indicated that multicollinearity among the correlated predictors was not problematic (tolerances ranged from .76-.88 and variance inflation factors (VIFs) ranged from 1.13-1.32). Results of the multiple regression analyses, in which we separately regressed each confidence in the courts criterion onto all four of the hypothesized predictors, are shown in Table 3.7 The first analysis found that only dispositional trust and cynicism were significant independent predictors of the single item measure of unspecified confidence in the courts. The second regression analysis revealed three significant independent predictors of confidence in the courts when it was operationalized with items pertaining to trustworthiness, with trust in institutions again failing to achieve significance. The final multiple regression again found three of the four predictors to independently predict confidence in the courts when operationalized as confident expectations of specific actions or attributes. This time, however, the non-significant predictor was obligation to obey. 


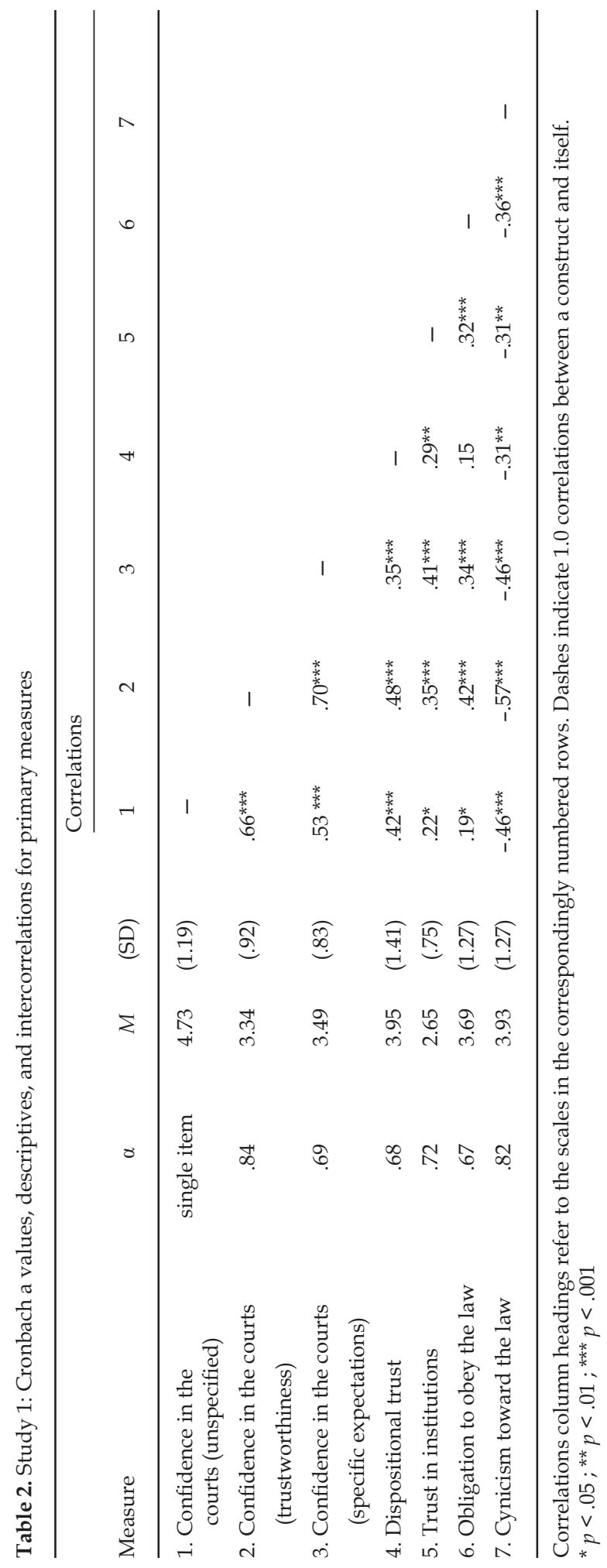


Table 3. Study 1: Unstandardized B (and standardized $\beta$ ) and standard error (SE) values for predictors in multiple regression models predicting each of the three confidence in the courts measures

\begin{tabular}{|c|c|c|c|c|c|c|c|c|c|}
\hline \multirow[t]{4}{*}{ Predictor } & \multicolumn{9}{|c|}{ Model B ( $\beta$ ) SE estimates } \\
\hline & \multicolumn{9}{|c|}{ Confidence in the courts measures } \\
\hline & \multicolumn{3}{|c|}{ Unspecified } & \multicolumn{3}{|c|}{ Trustworthiness } & \multicolumn{3}{|c|}{ Specific expectations } \\
\hline & $\beta$ & $\mathrm{SE}$ & $p$ & $\beta$ & SE & $p$ & $\beta$ & SE & $p$ \\
\hline Dispositional trust & .27 & $(.33)$ & $.07^{* * *}$ & .33 & $(.22)$ & $.05^{* * *}$ & .11 & (.18) & $.05^{*}$ \\
\hline Trust in institutions & .21 & (.13) & .15 & .12 & $(.09)$ & .11 & .32 & $(.26)$ & $.11^{* *}$ \\
\hline Obligation to obey the law & .03 & $(.03)$ & .08 & .15 & $(.21)$ & $.06^{*}$ & .09 & (.13) & .06 \\
\hline Cynicism toward the law & -.28 & $(-.31)$ & $.08^{* *}$ & -.26 & $(-.36)$ & $.06^{* * *}$ & -.17 & $(-.26)$ & $.06^{* *}$ \\
\hline Model statistics & \multicolumn{3}{|c|}{$\begin{array}{c}\text { adj } R^{2}=.31 \\
F(4,106)=13.21^{* *}\end{array}$} & \multicolumn{3}{|c|}{$\begin{aligned} \text { adj } R^{2} & =.46 \\
F(4,97) & =22.46^{* *}\end{aligned}$} & \multicolumn{3}{|c|}{$\begin{array}{c}\text { adj } R^{2}=.32 \\
F(4,104)=13.71^{* *}\end{array}$} \\
\hline
\end{tabular}

${ }^{*} p<.05 ;{ }^{* *} p<.01 ; * * * p<.001$

\section{Discussion}

Study 1 factor analyses and correlations among indexed scales supported the separability of the predictor constructs (see Figure 1), with four distinct factors that were moderately correlated. Although each predictor construct was correlated with all three operationalizations of confidence in the courts, multiple regression results varied across the specific operationalizations. This finding attests to the importance of carefully choosing and justifying one's specific operationalization of confidence in an institution, and empirically testing the generalizability of results to other operationalizations.

Surprisingly, although we had expected trust in institutions to be more closely related to confidence in the courts than dispositional trust, it was dispositional trust that had the more robust, independent relationship with specific confidence in the courts measures. It is possible that most college students have not formed strong enough opinions about the trustworthiness of local, state, and federal government for those three items to adequately assess individual differences in tendencies to trust institutions in typical college undergraduates.

\section{STUDY 2}

Study 2 was conducted to conceptually replicate the findings of Study 1, to assess the related construct scales' abilities to predict confidence in the courts over time as well as cross-sectionally, and to examine the test-retest reliability of the various measures. Thus, in Study 2, we shortened the survey and administered it twice over 11 weeks. We reduced the number of criterion variables to focus only on confidence in the courts assessed as trustworthiness because, unlike unspecified confidence, it contains more than one item (increasing its internal reliability), and because, unlike the specific expectations operationalization, it might be possible to revise the trustworthiness items to assess confidence in other specific institutions by simply changing the target of the items (e.g., to refer to the competence and integrity of "Congress," "banking institutions," etc., instead of "the courts"). It also was the criterion most related to our predictors in Study $1\left(R^{2}=.46\right.$, see Table 3$)$. We also expanded 
the trust in institutions scale to encompass more institutions likely to be salient and relevant to students. We predicted that broadening the trust in institutions scale in this way would increase the validity of that scale for our student sample, and also its ability to predict confidence in the courts.

\section{Method}

\section{Primary constructs and measures}

We used the same confidence in the courts (assessed as trustworthiness), cynicism, and dispositional trust scales as in Study 1. Four items referencing the President, the U.S. military, the Supreme Court, and the university's administration were added to assess trust in institutions. One obligation to obey item (specifically, "it is difficult to disobey the law and keep one's self-respect") was dropped during the process of shortening the survey because it seemed confusing and did not improve the scale's psychometric properties. ${ }^{8}$ Additionally, to explore how participants' confidence in the courts was affected by their contact with the legal system, we asked participants (at the second survey administration, 11 weeks after the first administration of the survey) if they had any contact with the criminal justice system in the intervening period. However, this variable was dropped from our analyses and from further discussion due to the low number of participants who had such contact. ${ }^{9}$

\section{Participants and data collection procedures}

A total of 204 undergraduate students from a University of Nebraska-Lincoln Introduction to Psychology course (multiple sections) completed an in-person survey at the beginning and/or end of the semester for research credit. One hundred seventy-three students were surveyed at Time 1 (T1, beginning of the semester) and 101 at Time 2 (T2, end of semester), with 70 students completing both T1 and T2 surveys. T1 participants had an average age of $19.33(\mathrm{SD}=.21)$ years and almost three-quarters of them were first-year students (gender information was not collected at T1). T2 participants were similar, having an average age of 19.6 (SD = $2.35)$ years, mostly first year $(75 \%)$, and approximately half $(53 \%)$ were female. Of the students who completed both pre- and post-measures, about half were female $(52 \%)$, and they had a mean age of 19.8 years (at $\mathrm{T} 1 ; \mathrm{SD}=2.73$ ).

\section{Results}

\section{Factor analyses}

Item factorability was determined using the same analyses as in Study 1 with similar results. At both T1 and T2, all item communalities were greater than .3 and all items

8. PCF analysis, using a four-factor criterion, of the Study 1 variables without the item yielded a factor solution accounting for $70 \%$ of the variance in responses and resulted in a nearly identical structure matrix. The scale's alpha decreased negligibly from .671 to .670 when the item was dropped.

9. Both between- and within-group comparisons were conducted. We found no significant differences relating to the contact with the criminal justice system. This is possibly because our analyses were underpowered (only 21 students reported having contact with the criminal justice system during the intervening period). 
correlated with at least one other item greater than .3. Exploratory factor analysis (PC extraction with an eigenvalue $>$ one criterion and Promax rotation) including the T1 dispositional trust, trust in institutions, obligation to obey, cynicism, and confidence in the courts items revealed a five-factor solution accounting for $61 \%$ of the variance in the responses. All related component scale items loaded highest (primary factor loadings $>.4$ ) on separate factors strongly associated with other items hypothesized as belonging to their scale, despite a moderate degree of multivocality (nine items had cross-loadings between .4 and .68). The confidence in the courts (trustworthiness) items loaded in parts on three of the five scales, with most items loading slightly higher on a factor not occupied by the items from the predictor scales. The four rotated factors - dispositional trust, trust in institutions, obligation to obey the law, and cynicism - again accounted for high to moderate proportions of the variance: trust in institutions $=27 \%$, confidence in the courts $=22 \%$, obligation to obey $=18 \%$, dispositional trust $=12 \%$, and cynicism $=10 \%$. Applying the same procedures to the same items at T2 also revealed a five-factor solution, accounting for $67 \%$ of the variance in responses. Once again, all related construct scales loaded highest on independent factors (primary loadings $>.40$ ) with moderate multivocality (11 items with crossloadings between .40 and .56). The confidence in the courts (trustworthiness) items seemed to load best on a factor not populated by items from the predictor scales, but some items also loaded on the other four factors.

We used the same procedures as in Study 1 (PC, eigenvalue $>1$, Promax rotation) to conduct a second set of factor analyses, including only items designed to assess the four predictors (dispositional trust, trust in institutions, obligation to obey, and cynicism). Applying these methods to T1 data resulted in a four-factor solution accounting for $62 \%$ of the variance in responses and left most scale items loading highest on their scale's factor, with a lesser degree of multivocality. The factor structure was much the same as in Study 1, except that one item intended to assess the trust in institutions factor ("I trust the United States military to do what's right") also loaded high on the obligation to obey scale (see Table 4). The rotated factors again accounted for high to acceptable proportions of the variance: trust in institutions = $32 \%$, obligation to obey $=18 \%$, cynicism $=16 \%$, and dispositional trust $=15 \%$ (univariate statistics and factor loadings reported in Table 4). As shown in Table 5, replicating this analysis with T2 data also showed that the expected rotated four-factor solution accounted for $69 \%$ of the variance in responses (trust in institutions $=36 \%$, cynicism $=20 \%$, dispositional trust $=17 \%$, and obligation to obey $=13 \%$ ). Consistent with what we found in Study 1 and at T1, the related construct scales all loaded highest together on independent factors (all primary loadings were over .65) and did not load as well on other factors (no cross-loadings over .55).

Principal axis factoring analysis of T1 data revealed a four-factor solution accounting for $49 \%$ of the variance in responses and confirmed three of our four above factors. As in the T1 PC analysis, items from the trust in institutions scale sometimes also loaded on the obligation to obey scale. All other scale items loaded together on independent factors. The same PAF methods applied to T2 data resulted in a four-factor solution with less multivocality than at T1 and accounted for $58 \%$ of the variance in responses.

T1-T2 scale reliability. As in Study 1, we created scales by averaging across the items belonging to each scale. As shown in Table 6, Cronbach $\alpha$ values were similar to those obtained in Study 1, and retest reliabilities indicated significant ordinal 
Table 4. Study 2: time 1 univariate statistics and factor loadings for exploratory principal components (Promax rotation) factor analysis of items assessing institutional confidence-related constructs

\begin{tabular}{|c|c|c|c|c|c|c|c|}
\hline \multirow[t]{2}{*}{ Items } & \multirow[b]{2}{*}{$M$} & \multirow[b]{2}{*}{ (SD) } & \multirow[b]{2}{*}{$N$} & \multicolumn{4}{|c|}{ Factor loadings } \\
\hline & & & & $\begin{array}{l}\text { Average } \\
\text { trust in } \\
\text { institutions }\end{array}$ & $\begin{array}{c}\text { Obligation } \\
\text { to obey } \\
\text { the law }\end{array}$ & $\begin{array}{c}\text { Cynicism } \\
\text { towards } \\
\text { the law }\end{array}$ & $\begin{array}{c}\text { Dispositional } \\
\text { trust }\end{array}$ \\
\hline \multicolumn{8}{|l|}{ Dispositional trust } \\
\hline Disp1 & 3.99 & $(1.43)$ & 172 & .44 & -.01 & -.08 & .73 \\
\hline Disp2 & 4.07 & $(1.27)$ & 173 & -.10 & -.17 & .23 & -.71 \\
\hline Disp3 & 3.88 & $(1.33)$ & 173 & .25 & .17 & -.06 & .81 \\
\hline \multicolumn{8}{|l|}{ Trust in institutions } \\
\hline Trust federal & 3.77 & (1.17) & 173 & .81 & .47 & -.28 & .23 \\
\hline Trust state & 3.56 & $(1.16)$ & 173 & .86 & .34 & -.21 & .23 \\
\hline Trust local & 3.36 & $(1.24)$ & 173 & .87 & .26 & -.24 & .27 \\
\hline Trust UNL & 2.87 & $(1.20)$ & 173 & .74 & .32 & -.14 & .35 \\
\hline Trust USSC & 2.99 & $(1.31)$ & 173 & .66 & .54 & -.16 & .09 \\
\hline Trust military & 3.05 & (1.49) & 173 & .63 & .64 & -.22 & .33 \\
\hline Trust President & 3.33 & $(1.13)$ & 173 & .71 & .25 & -.28 & .18 \\
\hline \multicolumn{8}{|l|}{ Obligation to obey the law } \\
\hline Accept legal authority & 3.01 & $(1.33)$ & 172 & .46 & .76 & -.35 & .24 \\
\hline Obey against morals & 3.25 & $(1.78)$ & 173 & .26 & .82 & -.16 & .06 \\
\hline \multicolumn{8}{|l|}{ Cynicism toward the law } \\
\hline Law represents powerful & 3.56 & $(1.60)$ & 173 & -.07 & -.20 & .76 & -.15 \\
\hline Law used to control me & 4.25 & $(1.52)$ & 173 & -.30 & -.19 & .80 & -.14 \\
\hline $\begin{array}{l}\text { Law doesn't protect } \\
\text { my interests }\end{array}$ & 5.12 & (1.23) & 173 & -.35 & -.28 & .76 & -.11 \\
\hline
\end{tabular}

Items are grouped by a priori scale. Loadings above .6 in bold. $M$; $=$ mean and $N=$ number of participants who responded to the question; $\mathrm{SD}=$ standard deviation.

Table 5. Study 2: time 2 univariate statistics and factor loadings for exploratory principal components (Promax rotation) factor analysis of items assessing institutional confidence-related constructs

\begin{tabular}{|c|c|c|c|c|c|c|c|}
\hline \multirow[t]{2}{*}{ Items } & \multirow[b]{2}{*}{$M$} & \multirow[b]{2}{*}{$(\mathrm{SD})$} & \multirow[b]{2}{*}{$N$} & \multicolumn{4}{|c|}{ Factor loadings } \\
\hline & & & & $\begin{array}{l}\text { Average } \\
\text { trust in } \\
\text { institutions }\end{array}$ & $\begin{array}{c}\text { Cynicism } \\
\text { towards } \\
\text { the law }\end{array}$ & $\begin{array}{c}\text { Dispositional } \\
\text { trust }\end{array}$ & $\begin{array}{c}\text { Obligation } \\
\text { to obey } \\
\text { the law }\end{array}$ \\
\hline \multicolumn{8}{|l|}{ Dispositional trust } \\
\hline Disp1 & 3.79 & $(1.35)$ & 101 & .32 & -.28 & .77 & .01 \\
\hline Disp2 & 3.94 & $(1.35)$ & 101 & -.31 & .19 & -.76 & -.20 \\
\hline Disp3 & 3.96 & (1.30) & 101 & .06 & -.08 & .80 & .10 \\
\hline \multicolumn{8}{|l|}{ Trust in institutions } \\
\hline Trust federal & 3.80 & $(1.34)$ & 101 & .87 & -.44 & .34 & .25 \\
\hline Trust state & 3.45 & $(1.35)$ & 101 & .88 & -.40 & .30 & .30 \\
\hline Trust local & 3.22 & $(1.28)$ & 101 & .88 & -.44 & .30 & .17 \\
\hline Trust UNL & 3.05 & (1.27) & 100 & .80 & -.30 & .20 & .30 \\
\hline Trust USSC & 2.88 & $(.13)$ & 101 & .76 & -.39 & .09 & .27 \\
\hline Trust military & 3.09 & (1.44) & 101 & .67 & .00 & .15 & .25 \\
\hline Trust President & 3.33 & (1.37) & 101 & .76 & -.08 & .32 & .29 \\
\hline \multicolumn{8}{|l|}{ Obligation to obey the law } \\
\hline Accept legal authority & 2.83 & $(1.34)$ & 101 & .45 & -.20 & .33 & .81 \\
\hline Obey against morals & 3.44 & $(1.80)$ & 101 & .19 & .03 & -.00 & .88 \\
\hline \multicolumn{8}{|l|}{ Cynicism toward the law } \\
\hline Law represents powerful & 3.50 & $(1.45)$ & 101 & -.26 & .88 & -.15 & -.07 \\
\hline Law used to control me & 4.08 & (1.48) & 101 & -.22 & .88 & -.18 & .06 \\
\hline $\begin{array}{l}\text { Law doesn't protect } \\
\text { my interests }\end{array}$ & 4.77 & $(1.22)$ & 101 & -.50 & .70 & -.30 & -.21 \\
\hline
\end{tabular}

Items are grouped by a priori scale. Loadings above .6 in bold. $M=$ mean and $N=$ number of participants who responded to the question; $\mathrm{SD}=$ standard deviation. 


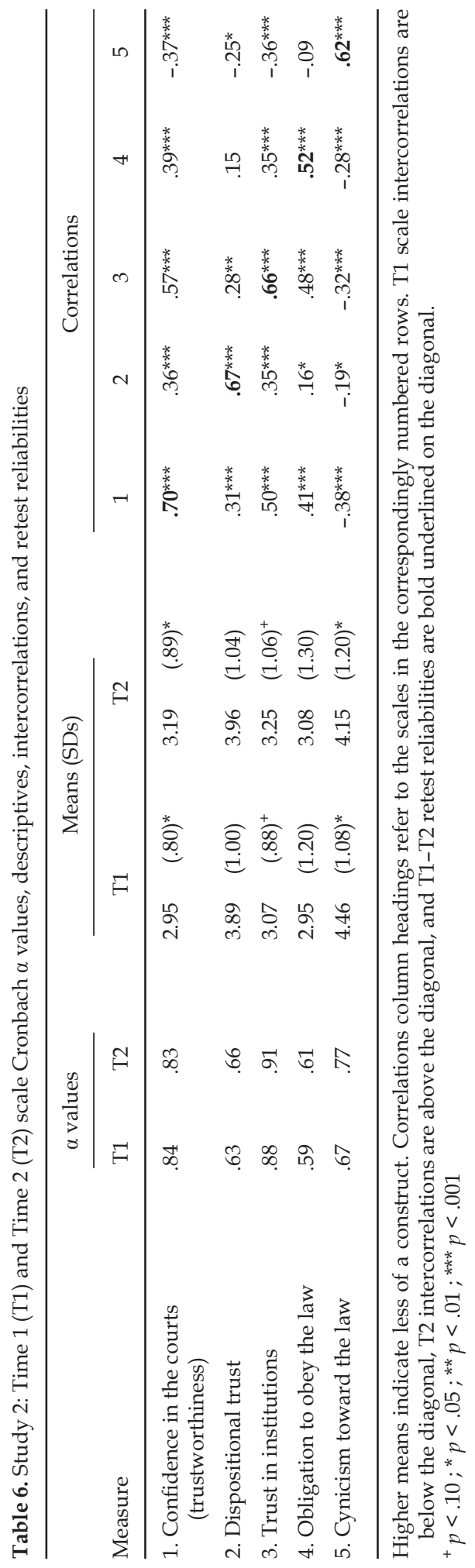


stability for all scales. Additionally, comparison of pre- and post-scores in Table 6 indicated that dispositional trust $\left(F(1,69)=.47, p=.51, \eta_{\mathrm{p}}^{2}=.01\right)$ and obligation to obey the law $\left(F(1,68)=.82, p=.37, \eta_{\mathrm{p}}^{2}=.01\right)$ did not change significantly between T1 and T2. However, cynicism toward the law increased significantly, $F(1,69)$ $=6.65, p=.01, \eta_{\mathrm{p}}^{2}=.09$, and confidence in the courts (assessed as perceived trustworthiness) significantly decreased, $F(1,67)=9.25, p=.003, \eta_{\mathrm{p}}^{2}=.12$, over the 11 weeks between data collection. In addition, there was a marginal decrease in trust in institutions which approached but did not reach statistical significance, $F(1,69)=$ $3.50, p=.07, \eta_{\mathrm{p}}^{2}=.05$.

Scale interrelationships. As shown in Table 6, all T1 and T2 scales were significantly correlated with the confidence in the courts (trustworthiness) measure and all T1 scales and most T2 scales were also significantly correlated with each other. However, at T2, obligation to obey the law was not significantly related to either cynicism toward the law or dispositional trust.

\section{Multiple regression analyses}

Replicating the analytical approach used in Study 1, we used multiple linear regression analyses to predict confidence in the courts (trustworthiness) from the dispositional trust, trust in institutions, obligation to obey, and cynicism at T1 and T2. In addition, to begin to investigate the possibility of causal directionality, we examined the ability of T1 variables to predict T2 confidence in the courts. As shown in Table 7, T1 analyses found that the predictors successfully predicted the T1 indexed institutional confidence (trustworthiness) score and indicated that all related construct scales were significant predictors of the criterion. Similarly, at T2, the predictors predicted the T2 indexed institutional confidence scale and dispositional trust, obligation to obey, and trust in institutions all had significant independent effects on the criterion while cynicism's independent effect approached significance ( $p=$ .06). Finally, the linear multiple regression analysis using $\mathrm{T} 1$ predictors to predict T2 confidence in the courts (trustworthiness) was significant. However, in this last analysis, only two of the T1 predictor scales were significant: obligation to obey and trust in institutions.

Table 7. Study 2: Unstandardized B (and standardized $\beta$ ) values and standard errors (SE) for predictors in three models predicting confidence in the courts operationalized as perceived trustworthiness

\begin{tabular}{|c|c|c|c|c|c|c|c|c|c|}
\hline \multirow[t]{3}{*}{ Predictor variables } & \multicolumn{9}{|c|}{ Model B ( $\beta)$ SE estimates } \\
\hline & \multicolumn{3}{|c|}{$\begin{array}{l}\text { T1 PVs predicting } \\
\text { T1 trustworthiness }\end{array}$} & \multicolumn{3}{|c|}{$\begin{array}{l}\text { T2 PVs predicting } \\
\text { T2 trustworthiness }\end{array}$} & \multicolumn{3}{|c|}{$\begin{array}{l}\text { T1 PVs predicting } \\
\text { T2 trustworthiness }\end{array}$} \\
\hline & $\beta$ & SE & $p$ & $\beta$ & SE & $p$ & $\beta$ & SE & $p$ \\
\hline Dispositional trust & .13 & $(.14)$ & $.06^{*}$ & .15 & (.18) & $.07^{*}$ & .13 & $(.15)$ & .10 \\
\hline Trust in institutions & .28 & $(.28)$ & $.08^{* * *}$ & .32 & $(.39)$ & $.07^{* * *}$ & .39 & $(.37)$ & $.12^{* *}$ \\
\hline Obligation to obey & .13 & $(.19)$ & $.05^{*}$ & .14 & $(.21)$ & $.06^{*}$ & .16 & $(.22)$ & $.08^{*}$ \\
\hline Cynicism toward the law & -.16 & $(-.20)$ & $.06^{* *}$ & -.12 & $(-.16)$ & $.06^{+}$ & -.12 & $(-.14)$ & .09 \\
\hline Model Statistics & \multicolumn{2}{|c|}{$\operatorname{adj} R^{2}=.32$} & $F(4,164)=20.41^{* * *}$ & \multicolumn{2}{|c|}{$F(4,94)=17.84^{\star * *}$} & $* * *$ & \multicolumn{3}{|c|}{$\operatorname{adj} R^{2}=.34$} \\
\hline
\end{tabular}

T1, Time 1; T2, Time 2. PV, predictor variable; CV, criterion variable.

$+p<.10 ;{ }^{*} p<.05 ;{ }^{* *} p<.01 ;{ }^{* * *} p<.001$ 


\section{GENERAL DISCUSSION}

These two studies examined institutional confidence-related constructs, over time, and their ability to predict confidence in the courts. Conceptualizations and measures found in the literature suggested four potentially separable confidence-related constructs: dispositional trust, trust in institutions, felt obligation to obey the law, and cynicism toward the law. We hypothesized that, because of differences in valence and emphases on different targets and expectations, these constructs would independently contribute to and predict students' confidence in the courts.

The results from the two studies provide preliminary evidence that the institutional confidence-related constructs we examined are indeed separable, and that items relating to these constructs do measure different, underlying phenomena. Factor analyses found that items intended to assess dispositional trust, trust in institutions, obligation to obey the law, and cynicism toward the law, in general, loaded on separate factors. Scales constructed from the items used in this study were intercorrelated, as expected, but not overly so, further attesting to the separability of the constructs. Although other distinctions may be possible and fruitful, these findings provide evidence that items assessing the four confidence-related constructs we examined can be reliably distinguished. Conceptually, the constructs vary in target breadth, expectational focus, and valence, suggesting that such dimensions are important to consider when distinguishing among confidence-related constructs in the literature.

In both studies, regression analyses provide some converging, albeit still mixed, evidence for the independent utility of these four confidence-related constructs for predicting confidence in the courts. For example, dispositional trust was always related to, and independently predicted, the various operationalizations of confidence in the courts that were assessed at the same time. This supports the expected conceptual overlap in dispositions to trust in general, and having confidence in the courts specifically. Similarly, cynicism was independently predictive of confidence in the courts (across operationalizations) in Study 1, and also at T1 (and marginally at T2) in Study 2. This suggests the importance of considering negative-valenced sources of confidence in the courts in addition to positive sources. It is also consistent with others' (e.g., Cook \& Gronke, 2005) claims of the importance of considering both positive and negative aspects of confidence in institutions (e.g., active trust and distrust).

In contrast, the constructs of obligation to obey the law and trust in institutions were somewhat less robust in their ability to predict the various operationalizations of confidence in the courts. Obligation to obey the law was consistently a significant independent predictor of confidence in the courts (assessed as trustworthiness) for both Studies 1 and 2, and across both T1 and T2 results within Study 2. In addition, and unlike dispositional trust and cynicism toward the law, obligation to obey the law and trust in institutions at T1 predicted confidence in (perceived trustworthiness of) the courts at T2. This suggests that not only do obligation to obey the law and trust in institutions have conceptual overlap with perceived trustworthiness of the courts at one point in time, but that they may play a role in the maintenance of trustworthiness perceptions over time.

On the other hand, in Study 1, obligation to obey was not independently predictive of the other two operationalizations of confidence in the courts (unspecified confidence in the courts and specific expectations of the courts). Trust in institutions also only accounted for independent variance on one of the operationalizations of 
confidence in the courts (specific expectations) in Study 1. In general, the fact that the predictors differed in their predictive ability depending on how confidence in the courts was operationalized suggests, consistent with other research (e.g., Cook \& Gronke, 2005; Gibson, Caldeira \& Spence, 2003), that different operationalizations are likely assessing at least somewhat different phenomena. More research on these different operationalizations and their implications is needed.

It is also intriguing that, in Study 1, dispositional trust (the most diffuse form of trust, with the most general target) was more predictive of two of the three measures of confidence in the courts than was trust in institutions. This was reflected in both the simple correlation and the multiple regression results. This finding seems incongruent with the idea that there should be more conceptual overlap between trust in institutions, in general, and trust in the courts, specifically, than between dispositional trust and trust in the courts. Perhaps measures of trust in other institutions, rather than trust in various levels of government as they are measured here, would prove more predictive. It is possible that the lesser predictive ability of trust in institutions may have been attributable to the students in our sample having had less experience with the institutions we asked about in Study 1. In Study 2, when we included additional items relevant and salient to students (e.g., the President, the U.S. military, the university's administration), the expected higher relationship with unspecified institutional confidence emerged (again, both in the correlation and regression results)..$^{10}$

The stability of scales over time in Study 2, indicating retest reliabilities ranging from correlations of .52 to .70, is noteworthy. Although participants' scores did not all remain static over time in Study 2 (some scores significantly increased or decreased), their standing on the scales were quite stable relative to one another, as would be expected if there were no major influences on some of the students but not others. The fact that some of the confidence-related constructs changed and others did not is in itself interesting. To the extent that dispositional trust is a traitlike construct, one would not expect it to change, and it did not. Similarly, some have noted that obligation to obey the courts is a particularly widespread value, even among individuals who express low confidence in the courts (Gibson, Caldeira, \& Spence, 2003), and this could explain the lack of change in obligation to obey the law, even while participants changed on other confidence-related scales. Regarding those scales, further research will need to be conducted to assess whether changes in scores over time are related to common student experiences (e.g., students may become more cynical to the courts and to other governmental institutions during their first year of college as they learn about relativism in a variety of contexts) or other factors, including whether there might be weaknesses in the conceptualization or measurements of the constructs. In addition, there are reasons to believe there will be differences in the explanatory power of various confidencerelated constructs over time and because of experiences, including the likelihood

10. We examined the impact of improving the trust in institutions scale by also conducting the regressions using a version of the trust in institutions scale identical to that used in Study 1 . Standardized beta values using the three-item version of the scale were similar and only slightly less than the current seven-item scale (T1, .26; T2, .39, T1 $\rightarrow \mathrm{T} 2, .40)$. Although these results might suggest that the inclusion of the additional items had little impact in Study 2, it is possible that the inclusion of the additional items (which were in the same part of the survey as the other general trust in institution items) created a cognitive priming effect of multiple relevant institutions that impacted the interpretation, and improved the validity, of the original three items for assessing general institutional trust in the college population. 
that dispositional variables will become less predictive when one has more institutional experiences (whatever it means to have "experiences" - again, there also may be a valence issue, such that if the experiences are positive they may have a different impact than if they are negative) (D'Amico, 2003; Kramer, 1999; Mayer et al., 1995/2006; Tyler, 1990/2006).

Our study is not without limitations. First, our findings may be somewhat tempered because of the sample we surveyed. Our study used undergraduate students. Though their generalizability is unknown, data indicate the students comprise a group that has numerous arrests because of aggressive local and campus enforcement of alcohol-related offenses (Newman, Shell, Major, \& Workman, 2006) ${ }^{11}$ and thus likely would have had court hearings for misdemeanor offenses relating to alcohol and other substance use, as well as traffic matters (see also Hayford \& Frutsenberg, 2008).

In addition, there is room for improvement in the scales. For example, in some of our analyses, items from the trust in institutions scale loaded more highly than expected on the obligation to obey scale, suggesting the need for the items to distinguish constructs more clearly. On the other hand, the items from the general trust in institutions scale with the highest loadings on obligation to obey the law were those specific items relating to trust in the law (i.e., the courts and the military). These findings were not surprising given the theoretical overlap between the constructstrusting a specific institution to do what is right should associate with greater obedience to that institution (Tyler, 1990/2006). This is likely to be a problem whenever a general construct is assessed by averaging across specific responses. In addition, the Cronbach $\alpha$ internal reliability estimates were sometimes below .7, and our factor analysis results were less clear when PAF procedures were used rather than PC analysis procedures. Given the relatively small number of items assessing several of the different constructs, these results may be due to under-specification of the separable constructs. This limitation, again, argues the need for more attention to measure development efforts that better capture the constructs.

Despite the limitations of our research, these two studies begin the task of identifying separable, confidence-related constructs, and examining the extent to which they may provide potentially independent sources of confidence in the courts. Further studies will need to be conducted to sort out the psychometric and psychological issues when using the terms confidence, trust, legitimacy, loyalty and so on. Of course, future research should also be conducted on samples beyond college students, who might differ from other segments of the population in terms of their institutional confidence. Most critically, though, future research should continue to focus on the items that can be used to reliably and validly measure confidence-related constructs. Ideally, the measures should be the same, or at least similar, whether the institution being studied is the courts, the health care system, a local government, and so on.

Insofar as the courts are concerned, our research approach dovetails nicely with the practical advice given to courts by the National Center for State Courts regarding the need to intentionally and systematically measure institutional confidence (2005). The administrative policy interest in ensuring the public's confidence in the courts (National Center for State Courts, 1999, 2000) will be furthered not only

11. More recent data reveal that over half (503) of the arrests at the university in $2008(N=911)$ were of 18- to 20-year-olds, and in the city itself, there were more arrests $(4,267)$ among 18 - to 20 -yearolds than any other age cohort (total number of arrests in Lincoln for 2008 was 18,783) (Nebraska Crime Commission, n.d.). 
by enabling courts to benchmark the public's confidence and allow comparisons across courts, but also by comparing the judicial institution to other institutions. It also will allow comprehensive understanding of the link between performance and confidence in the institutional context (Yang \& Holzer, 2006).

Although exploratory, our studies are unique in simultaneously examining multiple confidence-related items and scales, with many items re-administered after a delay, in order to determine the relative independence of and overlap among the identified constructs, and their relationships to confidence in the courts over time. What seems to be indicated by our findings is that researchers should carefully select the institutional confidence-related items (and scales) they use, and they should be explicit about their operationalizations. This will allow the field to advance, as well as allowing readers to better understand and assess the research. Our research is one such step toward the much-needed clarification of what has been called the "conceptual morass" (Barber, 1983, p. 1) and "quagmire" (Metlay, 1999, p. 1) plaguing the social science of institutional confidence.

Acknowledgments - This research was supported in part upon work supported by the National Institute of Justice (NIJ) under grant number 2008-IJ-CX-0022 and by the National Science Foundation (NSF) under grant numbers IIS-0535255 and CMMI-0709333. Joseph Hamm's participation was supported in part by an NSF IGERT fellowship, DGE- 0903469. Any opinions, findings, and conclusions or recommendations expressed in this material are those of the authors and do not necessarily reflect the views of NIJ or NSF.

\section{REFERENCES}

Barber, B. (1983). The logic and limits of trust. New Brunswick, NJ: Rutgers University Press.

Benesh, S. C. (2006). Understanding public confidence in American courts. Journal of Politics, 68, 697-707.

Benesh, S. C., \& Howell, S. (2001). Confidence in the courts: A comparison of users and non-users. Behavioral Sciences \& the Law, 19, 199-214.

Bigley, G. A., \& Pearce, J. L. (1998). Straining for shared meaning in organization science: Problems of trust and distrust. Academy of Management Review, 23, 405-421.

Cook, T. E., \& Gronke, P. (2005). The skeptical American: Revisiting the meanings of trust in government and confidence in institutions. The Journal of Politics, 67, 784-803.

D’Amico, L. C. (2003). Examining determinants of managerial trust: Evidence from a laboratory experiment. Paper presented at the National Public Management Research Conference, Washington, D.C. Retrieved from http://www.pmranet.org/conferences/georgetownpapers/DAmico.pdf

Dougherty, G. W., Lindquist, S. A., \& Bradbury, M. D. (2006). Evaluating performance in state judicial institutions: Trust and confidence in the Georgia judiciary. State and Local Government Review, 38, 176-190.

Gastil, J., Deess, E. P., Weiser, P., \& Simmons, C. (2010). The jury and democracy: How jury deliberation promotes civic engagement and political participation. New York: Oxford University Press.

Gibson, J. L. (2008). Challenges to the impartiality of state supreme courts: Legitimacy theory and "new-style" judicial campaigns. American Political Science Review. 102, 59-75.

Gibson, J. L., Caldeira, G. A., \& Spence, L. K. (2003). Measuring attitudes toward the United States Supreme Court. American Journal of Political Science, 47, 354-367.

Gibson, J. L., \& Caldeira, G. A. (1998). Changes in the legitimacy of the European Court of Justice: A post- Maastricht analysis. British Journal of Political Science 28, 63-91.

Goldberg, L. R. (1999). A broad-bandwidth, public domain, personality inventory measuring the lower-level facets of several five-factor models. In I. Mervielde, \& I. Deary, \& F. De Fruyt, \& F. Ostendorf (Eds.), Personality Psychology in Europe (Vol. 7, pp. 7-28). Tilburg, The Netherlands: Tilburg University Press.

Gross, K., Brewer, P. R., \& Aday, S. (2009). Confidence in government and emotional responses to terrorism after September 11, 2001. American Politics Research, 37, 107-128.

Hall, M. A., Dugan, E., Zheng, B., \& Mishra, A. K. (2001). Trust in physicians and medical institutions: What is it, can it be measured, and does it matter? The Milbank Quarterly, 79, 613-639.

Hardin, R. (2006). Trust. Malden, MA: Polity Press. 
Hayford, S. R., \& Furstenberg, F. F. (2008). Delayed adulthood, delayed desistance? Trends in the age distribution of problem behaviors. Journal of Research on Adolescence, 18, 285-304.

Hoy, W. K., \& Tschannen-Moran, M. (2003). The conceptualization and measurement of faculty trust in schools: The omnibus T-Scale. In W. K. Hoy, \& C. Miskel (Eds.), Studies in leading and organizing schools (pp. 181-208). Greenwich, CT: Information Age.

Huberty, C. J. (1994). A note on interpreting an R2 value. Journal of Educational and Behavioral Statistics, 19, 351-356.

Kramer, R. M. (1999). Trust and distrust in organizations: Emerging perspectives, enduring questions. Annual Review of Psychology, 50, 569-598.

Leben, S. (1999). (Ed.). Public trust and confidence in the courts: A national conference and beyond [Special issue]. Court Review 36, (3).

Lewicki, R. J., McAllister, D. J., \& Bies, R. J. (1998). Trust and distrust: New relationships and realities. Academy of Management Review, 23, 438-458.

Mayer, R. C., Davis, J. H., \& Schoorman, F. D. (2006). An integrative model of organizational trust. In R. M. Kramer (Ed.), Organizational trust: A reader (pp. 82-108). Oxford: Oxford University Press. (Reprinted from Academy of Management Review 20 709-734 1995.).

Metlay, D. (1999). Institutional trust and confidence: A journey into a conceptual quagmire. In G. T. Cvetkovich, \& R. E. Lofstedt (Eds.), Social trust and the management of risk (pp. 100-116). London: Earthscan.

Nannestad, P. (2008). What have we learned about generalized trust, if anything? Annual Review of Political Science, 11, 413-436.

National Center for State Courts. (1999, May). How the public views the state courts: A 1999 national survey. Williamsburg, VA: National Center for State Courts. Retrieved from http://www.ncsconline. org/WC/Publications/Res-AmtPTC-- PublicViewCrtsPub.pdf

National Center for State Courts. (2000). National action plan: A guide for state and national organizations. Williamsburg, VA: Author. Retrieved from http://contentdm.ncsconline.org/cgi-bin/showfile. exe?CISOROOT $=/$ ctcomm\&CISOPTR $=20$

National Center for State Courts. (2005). Trial court performance standards and measurement system. Williamsburg, VA: Author. Retrieved from http://www.ncsconline.org/D-Research/tcps/index. $\underline{\mathrm{html}}$

Nebraska Crime Commission on Law Enforcement and Criminal Justice. (n.d.). Arrest and offense data. Retrieved from http://www.ncc.state.ne.us/statistics/data-search/arrest.htm

Newman, I. M., Shell, D. F., Major, L. J., \& Workman, T. A. (2006). Use of policy, education, and enforcement to reduce binge drinking among university students: The NU Directions project. International Journal of Drug Policy, 17, 339-349.

Newton, K. (2001). Trust, social capital, civil society, and democracy. International Political Science Review, 22, 201-214.

O'Connor, S. D. (1999). Dimension of equal justice: Some suggestions to increase public trust. Court Review, 36(3), 7-13.

Rotter, J. B. (1967). A new scale for the measurement of interpersonal trust. Journal of Personality, 35, $651-665$.

Rotter, J. B. (1971). Generalized expectancies for interpersonal trust. American Psychologist, 26, 651-665.

Rottman, D., \& Tomkins, A. J. (1999). Public trust and confidence in the courts: What public opinion surveys mean to judges. Court Review, 36(3), 24-31.

Rousseau, D. M., Sitkin, S. B., Burt, R. S., \& Camerer, C. (1998). Not so different after all: A cross-discipline view of trust. Academy of Management Review, 23, 393-404.

Suchman, M. C. (1995). Managing legitimacy: Strategic and institutional approaches. Academy of Management Review, 20, 571-610.

Tyler, T. R., \& Fagan, J. (2008). Legitimacy and cooperation: Why do people help the police fight crime in their communities? Ohio State Journal of Criminal Law, 6, 231-275.

Tyler, T. R. (2006). Why people obey the law: Procedural justice, legitimacy, and compliance. Princeton: Princeton University Press. (Original work published 1990.).

Tyler, T. R., \& Huo, Y. J. (2002). Trust in the law: Encouraging public cooperation with the police and courts. New York: Russell-Sage Foundation.

University of Nebraska Public Policy Center. (2009). Taking Charge: Survey discussion and report. Lincoln, NE. Retrieved from http://ppc.unl.edu/publication/ TakingChargeSurveyandDiscussionReport

Warner, R. (2007). Applied statistics: From bivariate through multivariate techniques. New York: Sage Publications.

Wenzel, J. P., Bowler, S., \& Lanoue, D. J. (2003). The sources of public confidence in state courts: Experience and institutions. American Politics Research, 31, 191-211.

Yang, K., \& Holzer, M. (2006). The performance-trust link: Implications for performance measurement. Public Administration Review, 66, 114-126. 


\section{Appendix: Survey Scales and Items Administered in Each Study and at Each Contact}

Study 1 Study 2

Item/scale $\mathrm{T} 1 \mathrm{~T} 2$

Confidence in the courts (unspecified)

Consider the courts in your community. On a scale of 1 to 7 , how would you rate your confidence in the courts? The lower the number, the less confidence you have; the higher the number, the more confidence you have. (reverse scored)

Confidence in the courts (trustworthiness)

Most judges in my community do their job well.

Most judges in my community treat people with respect.

The basic rights of citizens in my community are well protected by the police.

The judges in my community have too much power.

Most judges in my community are dishonest.

Most judges in my community treat some people better than others. (reverse scored)

Confidence in the courts (specific expectations)

Courts protect defendants' constitutional rights.

Most juries are not representative of the community. (reverse scored)

Judges are generally honest and fair in deciding cases.

Judges do not give adequate attention and time to each individual case. (reverse scored)

Courts are out of touch with what's going on in their communities. (reverse scored)

Courts do not make sure their orders are enforced. (reverse scored)

\section{Dispositional trust}

Generally speaking, would you say that most people can be trusted (1), or that you can't be too careful (7)?

Do you think that most people would take advantage of you if they got the chance (1) or would they try to be fair (7)? (reverse scored)

Would you say that most of the time people try to be helpful (1) or that people are just looking out for themselves(7)?

Trust in institutions

How much of the time do you feel you can trust the federal government in Washington, D.C., to do what's right?

How much of the time do you feel you can trust the state government to do what's right?

How much of the time do you feel you can trust the local government to do what's right?

How much of the time do you feel you can trust the administration at the University of XXX to do what's right?

How much of the time do you feel you can trust the United States Supreme Court to do what's right?

How much of the time do you feel you can trust the United States military to do what's right?

How much of the time do you feel you can trust the President to do what's right?

Obligation to obey the law

I feel I should accept decisions made by legal authorities.

People should obey the law even when it goes against what they think is right.

It is difficult to break the law and keep one's self-respect.

Cynicism toward the law

The law represents the values of people in power rather than the values of people like me.

People in power use the law to try to control people like me.

The law does not protect my interests.

\section{$\mathrm{X}$}

$x \quad x-x$

$x \quad x \quad x$

$x \quad x$

$x \quad x \quad x$

$x \quad x$

x $\quad x$

$x$

$\mathrm{x}$

X

$x$

$\mathrm{x}$

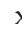

$\mathrm{x}$

X

$x$

$x$ $x$

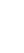

All items were accompanied by a seven-point ( 1 = strongly agree, 7 = strongly disagree $)$ scale except for the dispositional trust items which used item-specific seven-point bipolar scales anchored with different descriptives (e.g., "helpful" vs. "look out only for themselves) at the extremes. 